\title{
Projeto de extensão: capacitação de jovens pecuaristas do município de Vista Gaúcha - RS
}

\author{
Gabriel Nunes de Oliveira, João Pedro Velho, Nilson Luiz Costa
}

https://doi.org/10.4322/mp.978-65-991393-1-4.c4

\section{Introdução}

Segundo a Constituição brasileira, materializada na Lei $n^{0} 11.326$ de julho de 2006, considera-se como agricultora familiar aquela que desenvolve atividades econômicas no meio rural e que observa alguns aspectos básicos como: não possuir propriedade rural maior que 4 módulos fiscais, utilizar predominantemente mão de obra da própria família nas atividades econômicas da propriedade, possuir a maior parte da renda familiar proveniente das atividades agropecuárias desenvolvidas no estabelecimento rural.

Segundo o Censo Agropecuário de 2006, no Brasil havia 4.366.267 estabelecimentos rurais familiares, sendo que no estado do Rio Grande do Sul, encontravam-se 378.353 estabelecimentos, ou seja, $8,67 \%$ do total brasileiro. Os estabelecimentos rurais familiares nesse estado representam $85,7 \%$ do total de estabelecimentos, que perfaz um total de 441.472 propriedades, obtendo uma receita de 6,9 bilhões de reais, ou $44,23 \%$ do total de 15,6 bilhões de reais de todas as propriedades rurais.

O presente texto tem objetivo de descrever a forma de atuação no processo de sucessão familiar no âmbito da agricultura familiar a partir da experiência de uma ação de extensão da Universidade Federal de Santa Maria, Campus de Palmeira das Missões desenvolvida junto a produtores de leite do município de Vista Gaúcha juntamente com a prefeitura municipal, localizado na região noroeste do estado do Rio Grande do Sul.

Seu objetivo centra-se no desenvolvimento de um ambiente propício dentro das propriedades rurais de característica familiar, no sentido de garantir a sustentabilidade socioeconômica e ambiental dos que ali residem e trabalham, possibilitando a perpetuação das gerações que ali vivem e se sustentam, de acordo com suas vontades e vocações.

Nesse sentido, a materialização desse objetivo passa pela qualificação dos processos produtivos e de gerenciamento da atividade, alcançando não apenas a geração que atualmente comanda o processo, mas também garantindo que as gerações futuras, poderão reproduzir essa forma de vida em níveis superiores.

Isso significa trabalhar não apenas com técnicas de produção e de gestão, mas também desenvolver um ambiente amigável ao processo de sucessão geracional, indo além das questões econômico-financeiras para submergir no universo das relações familiares. 
A despeito de serem atividades desenvolvidas no âmbito rural, essas propriedades caracterizam-se por serem essencialmente familiares, pois como bem destaca Lodi (1987), trata-se do empreendimento em que a sucessão é vinculada a fatores hereditários onde as concepções percebidas nessa "organização" estão intimamente vinculadas ao sobrenome da família ou com a imagem da pessoa que constituiu 0 empreendimento. Nessa linha, Donneley (1964), ressalta que as empresas familiares possuem objetivos e razão de ser equiparadas com uma família ao longo de ao menos duas gerações, atentando para o fato de que essa equiparação provoca influição mútua entre a direção do negócio e os objetivos da família.

É nesse ambiente que as ações de formação e qualificação dos atores da agricultura familiar deverão se desenrolar, alcançando e desenvolvendo conhecimento mutuamente elaborados, de modo a estabelecer uma sinergia capaz de superar os obstáculos geracionais e de níveis diferenciados de conhecimento, permitindo que a empresa familiar rural tenha condições de manter-se na atividade produtiva ao longo de gerações.

\section{A empresa familiar}

Buscando entender o que seja uma empresa familiar, podemos recorrer a Werner (2004), que define empresa familiar como sendo gerada a partir de uma pessoa, que fundou e desenvolveu-a e que, com o passar do tempo, incorporou membros da família no intuito de suprir sua eventual ausência, dando sequência na linha de comando.

Para Adachi (2006), a chave da descrição de uma empresa familiar, está na interferência que a família pode realizar sobre o comando societário e dos negócios. De forma pontual, Gallo (1995) destaca que na análise dos diversos conceitos de empresas familiares, há uma convergência de delimitação de empresas familiares em três aspectos: propriedade ou o controle sobre a empresa; o poder exercido pela família sobre a empresa, principalmente pelo trabalho nela executado pelos membros da família; e a vontade de transmitir a empresa a futuras gerações o que se materializa na inclusão de membros das futuras gerações na empresa.

Para constatar relações entre empresa e família, Bernhoeft (1989) identifica que os laços da família constituem um fator, entre outros, que determina a sucessão nos cargos administrativos. Os laços consanguíneos como os filhos e sentimentais como a esposa dos atuais ou antigos dirigentes conduze-os ao centro das decisões. No tocante aos valores institucionais da empresa, há uma identificação dessas com os valores da própria família e as ações dos membros da família repercute na imagem da empresa. Por fim, o autor destaca que cada membro da família deverá estabelecer um acordo com os demais familiares no que diz respeito às suas relações com a empresa, determinando o seu próprio destino.

Bernhoeft (1989) complementa o estabelecimento dessas relações destacando que há uma forte valorização da confiança mútua, independente de vínculos familiares, como são os casos de funcionários que iniciaram nas atividades da empresa juntamente com os fundadores. Os laços afetivos são fortes o suficiente para influenciar comportamentos, relacionamentos e decisões da empresa. A valorização da antiguidade apresenta-se como um atributo que se sobrepõe a eficácia ou competência. Também a dedicação é destacada, chegando a exigência de declinação da vida pessoal em detrimento ao sucesso da empresa, bem como há uma grande dificuldade na separação entre o que é emocional e o que é racional, sendo que normalmente predomina o emocional. 
Essas são características que podem apresentar vieses positivos e negativos e nesse sentido, Lodi (1998) destaca que a empresa familiar, pela sua constituição e natureza, possui características que são danosas ao seu desenvolvimento, sendo as principais:

a. A falta de normas, pode haver uso impróprio dos recursos da empresa por membros da família que pode levar a empresa à situação de instabilidade e dificuldades financeiras.

b. Deficiência na visão empresarial pode levar a falta de sistema de planejamento e de procedimentos formais de gestão, que pode trazer problemas no processo produtivo e financeiro da empresa.

c. Divergência de interesses entre família e empresa, que pode resultar em descapitalização da empresa, problema na gestão empresarial;

d. A resistência a aceitação de modernização do processo de gestão, de produção, pode afetar diretamente na competitividade.

e. O não estabelecimento de ações de capacitação e de desenvolvimento das pessoas pode alçar ao poder pessoas não habilitadas ao seu desempenho.

Essas questões abordadas até o momento, remete-nos ao destaque de Werner (2004) que salienta $o$ fato de que não se pode analisar uma empresa familiar desconsiderando a dinâmica familiar, da mesma forma, não se pode analisar a dinâmica familiar desconsiderando o seu relacionamento com a sua empresa.

Podemos estender essas argumentações à agricultura familiar, na medida em que desfruta das características até aqui apresentadas da empresa familiar. A despeito de algumas especificidades da agricultura familiar, na essência, o empreendimento da agricultura familiar, de um modo geral, é gerado a partir de uma pessoa, que se desenvolve com o passar do tempo, onde os membros da família suprem a mão-deobra e concorrem na linha de comando.

Há um expresso poder da família sobre as atividades da empresa, que se solidifica em muito, pela participação dos membros da família nas atividades empresariais. Além disso, de um modo geral, há a expressa vontade por parte dos detentores do controle em transmitir a empresa a futuras gerações.

A consideração de (Gersik et al., 1997) sobre a dificuldade de um CEO (Chief Executive Officer) ao gerenciar uma empresa onde o poder é dividido com um irmão, sobrinho, ou outro grau de parentesco ou afetivo, também pode ser estendido à agricultura familiar, tendo em vista que em ambas há aspectos positivos e negativos. Por exemplo, a intimidade, possibilita que as partes entendam as preferencias, as forças e fraquezas uns dos outros e até mesmo, seja entendido e esperado o auto sacrifício dos membros familiares. O ambiente harmônico pode gerar sentimento de pertencimento e com isso comprometendo os membros, garantindo uma visão de longo prazo, bem como a adoção rápida de ações. No entanto, sublinham os autores, que essa mesma relação de intimidade pode estabelecer um ambiente adverso a necessidade de profissionalismo na condução dos negócios.

Dessa forma, a empresa familiar, no nosso caso agricultura familiar, possui uma demanda por uma diferenciação em relação às empresas não familiares e nesse sentido, Gersick et al. 1997, analisam a evolução da empresa familiar sob a ótica de três dimensões a saber: a família, a propriedade e a gestão /empresa, o que permite uma melhor compreensão da intersecção que há entre as questões familiares e a gestão da empresa.

Em algum momento, a empresa familiar enfrentará um processo sucessório e nesse sentido, Bernhoeft e Gallo (2003) destacam que para que essa sucessão ocorra sem 
traumas, é necessário planejamento, esforço e paciência, devendo ser feita ao longo do tempo, não somente quando da falta do fundador, ou detentor do controle da empresa. Complementarmente, Souza (2013) destaca que tradicionalmente, as empresas familiares impõe responsabilidades aos sucessores, que não raro, não tem a devida capacitação para exercer as funções que lhes estão sendo delegadas. Nessa mesma linha, Bernhoeft e Gallo (2003), lembram que: "ser filho de um pai brilhante é um desafio para o qual muitos herdeiros não estão preparados".

É nesse contexto que devemos planejar o processo de sucessão das empresas familiares, discutindo que será um processo inevitável e que será melhor que todos estejam preparados para tal. Dessa forma, não se trata de uma ação de curto prazo, mas sim, de longo prazo, onde a família deve estar ciente do que e por que fazer. Deve estar capacitada sobre os aspectos técnicos e gerenciais que envolvem a atividade empresarial e nessa direção, toda a estrutura patrimonial deve ser estruturada para levar a cabo esse planejamento, que reafirmamos ser de longo prazo.

A capacitação, deve ser um processo, que significa, ter um início, mas não ter um fim. Os Jovens, deverão ser inseridos nas discussões tão logo tenham maturidade para tanto. Não deve haver distinção de gênero (mulheres e homens), pois além de ser o certo a fazer, pois discriminação é algo repudiável, não há garantia nenhuma que uma mulher não irá assumir os negócios da família. Embora experiência seja importante na condução dos negócios, a interação com novas ideias, características dos jovens, deve ser perseguida.

Em fim, o processo de planejamento da sucessão, é um processo participativo e que deve ser apoiado em bases tecnológicas, tanto de gestão como de produção e para tanto, requer um constante processo de capacitação, seja através de treinamentos, palestras, cursos regulares, acesso das mais diversas mídias. Dessa forma, não deve ser visto como desperdício de tempo e sim como um investimento, tal qual como a empresa realiza ao comprar máquinas e equipamentos ou insumos modernos. Essa capacitação irá concorrer ao aumento da competitividade da empresa como todos os demais investimentos, ou até mais, pois possibilita potencializar os investimentos físicos realizados.

Destaca-se que uma empresa saudável economicamente, poderá garantir um processo sucessório sustentável, na medida que reduzirá os pontos de tensões entre os diversos membros, principalmente pelo fato de que a porta da empresa é a mesma porta da família, sendo impossível dissociar as questões empresariais das questões familiares.

\section{Referências}

Adachi P.P. Família S.A: gestão de empresa familiar e soluções de conflitos. São Paulo: Atlas. 2006.

Bernhoeft R. Empresa Familiar: sucessão profissionalizada ou sobrevivência comprometida. São Paulo: Nobel. 1989.

Bernhoeft R., e Gallo M. Governança na empresa familiar (7 ed. ed.). Rio de Janeiro: Elsevier. 2003.

Gallo M.A. Empresa Familiar: textos y casos. Barcelona: Praxis. 1995.

Gersik K., Davis J., Hampton M., Mccollon e Lansberg, I. De geração para geração: ciclos de vida da empresa familiar (2 ed. ed.). São Paulo: Negócio. 1997. 
Lodi J.B. A empresa familiar. São Paulo: Pioneira. 1998.

Souza E. O desafio do processo sucessório em uma empresa familiar: um estudo de caso em uma indústria de móveis. Revista Interdisciplinar de Estudos Contemporâneos 2013; 2: 91-103.

Werner R.A. Família \& Negócios: um caminho para o sucesso. Barueri, SP: Malone. 2004.

\section{Autores}

Gabriel Nunes de Oliveira ${ }^{1}$, João Pedro Velho ${ }^{2}$, Nilson Luiz Costa ${ }^{1}$

1. Professor Adjunto, Departamento de Ciências Econômicas, UFSM - Campus de Palmeira das Missões.

2. Professor Associado, Departamento de Zootecnia e Ciências Biológicas, UFSM Campus de Palmeira das Missões.Departamento de Tecnologia e Ciência dos Alimentos, Universidade Federal de Santa Maria - DTCA/UFSM, Avenida Roraíma, 1000, Prédio 42, sala 3211, 97105-900, Santa Maria - RS, Brasil. 